\title{
The effect of infertility upon quality of life and self-
} \section{esteem}

\begin{abstract}
Aim: In this study we aimed to determine the effect of infertility upon the quality of life and self-esteem and by this means guide nurses in taking care of and giving counseling to the infertile individuals.
\end{abstract}

Method: 150 individuals (100 females and 50 males) entered into the study, who came to be treated in the in vitro fertilization or IVF unit in the Medical Faculty Hospital at Bezmialem Foundation University between 26th July, 2016 and 26th January, 2017 and matched the research criteria. We collected the data using Information Form, Rosenberg Self Esteem Scale (RSES), and FertiQol (Fertility Quality of Life) Scoring. The obtained data was evaluated by applying independent samples t-test, ANOVA (Analyze of Variance) tests and Pearson Correlation using SPSS 22 (Statistical Program for Social Sciences) Packaged Software. The significance level was $\mathrm{p}<0.05$.

Results: We observed that out of the participants, $50 \%$ were between the ages of 26 ; and $30,38 \%$ were with a graduate or post-graduate education level, $81 \%$ are living in a nuclear family, and $65.3 \%$ are primarily infertile. It was seen that they expressed their feelings like that a substantial part of the individuals wereemotionally affected by infertility and $62 \%$ of them are very much upset by such a situation and unhappy. We discovered that the point average of the scores of RSES of the infertile individuals was $23.31 \pm 6.93$; in the females $23.05 \pm 6.95$, and $23.84 \pm 4.38$ in the males. We computed the point average of FertiQol as $76.63 \pm 6.86$; in the females $75.45 \pm 6.16$, and $78.89 \pm 4.86$ in the males. We found that in comparison of the scores by gender, there was a statistical significance between the point averages of RSES and FertiQol (respectively $p=0.049$, $p=<0.001)$. We determined that the sense of self-esteem in the infertile females is lower than that in the infertile males.

Conclusion: We determined that the socio-demographic, obstetric and infertility characteristics of the infertile individuals are effective upon their sense of quality of life and self-esteem. It is necessary and significant that an infertility nurse should take into consideration those characteristics in taking care of and giving counseling to the infertile individuals.

Keywords: an infertile individual, self-esteem, quality of life
Volume 7 Issue 3 - 2018

\author{
Nebahat Koca Çavdar,Anayit M Coșkun \\ Department of Nursing, Bezmialem Foundation University, \\ Turkey
}

Correspondence: Anayit M Coșkun, Departmant of Nursing, Bezmialem Foundation University, Silahtarağa st. No: 289, 34060, Alibeyköy, Eyüp / İstanbul,Turkey, Tel +90 53677467 04, Email coskunano@yahoo.com

Received: April 05, 2018| Published: May 22, 2018
Abbreviations: RSES, rosenberg self esteem scale; FertiQol, fertility quality of life scoring

\section{Introduction}

Infertility is the failure of a couple to become pregnant after one year of regular, unprotected intercourse. ${ }^{1}$ Primary infertility is being without any previous pregnancy while the fertility problems occurring in a couple that has conceived on their own and had a child in the past ending with the birth or not are called as secondary infertility., 2,3 World Health Organization (WHO) identified infertility as a social disease. ${ }^{1}$ It is suggested that the incidence of infertility is about 10 $15 \%$ among the couples at reproductive age and one out of every six or seven couples has an infertility problem. Almost more than 80 million people are affected from infertility. ${ }^{4,5}$ The incidence in Turkey resembles with world rates and it is estimated that $10-15 \%$ out of the couples have trouble with infertility. ${ }^{3,6}$ Since the beginning of human existence, fertility or reproduction has ever maintained its importance. Childbearing is an accepted, desired case in all communities so as to the development of society and the continuation of generations.
Therefore, the first studies of women's health issues are concentrated on diseases during pregnancy and maternity health. ${ }^{7-9}$ The social expectations like that the family elders are expecting from and pressing on the infertile couples to make a baby, lead to deepening and perpetuating of grief and sorrow in which they are. ${ }^{10-12}$ In the study of Kurçer et al. ${ }^{13} 42 \%$ of the married women attempted to seek a solution for bearing a child without completing one year, which reveals the fact that infertility is very crucial in the traditional societies like us. That study also suggests that most of women, regardless of education, occupation, or income level, go for the old-fashioned solutions. ${ }^{13}$ Infertility is a stressful case for the couples who want to have a baby and it is a part of life that is psychologically threatening, emotionally stressful, and economically expensive and in general, physically painful. ${ }^{7,14}$ In the infertile couples, the women feel guilt, stress and responsibility more than the males do. That's why even if the crux of infertility is not derived from them, the community puts the blame on women and because of this, they are fretting themselves in the treatment program. ${ }^{15}$ 
Under circumstances of infertility, which dramatically influences the social life, emotional situations, marriage relationship, self-esteem and body image of the infertile couples, the nurses have to show an integrated approach in consideration with these aspects. This study aimed to determine the effect of infertility upon the quality of life and self-esteem; and by this means guide nurses in taking care of and giving counseling to the infertile individuals.

\section{Research questions}

i. Does the gender of the infertile individuals affect the point average of RSES scores?

ii. Does the gender of the infertile individuals affect the point average of FertiQol scores?

iii. Is there a statistically significant difference between the point averages of RSES scores by the socio-demographic characteristics of the infertile individuals?

iv. Is there a statistically significant difference between the point averages of FertiQol scores by the socio-demographic characteristics of the infertile individuals?

$\mathrm{v}$. Is there a statistically significant difference between the point averages of RSES scores by the obstetric characteristics of the infertile individuals?

vi. Is there a statistically significant difference between the point averages of FertiQol scores by the obstetric characteristics of the infertile individuals?

vii. Is there a statistically significant relationship between the point averages of RSES and FertiQol scores in the infertile individuals?

\section{Method}

The research planned as descriptive was conducted between the dates of $7 / 26 / 2016$ and 1/26/2017 in the in vitro fertilization or IVF unit in the Medical Faculty Hospital at Bezmialem Foundation University. We identified the sample of research as 150 infertile patients including 100 females and 50 males, who were diagnosed with infertility, were literate, and entered into the study on a volunteer basis. We collected the data using 25-question introductory information form, RSES and FeriQol scoring in the method of face-to-face interviewing. For the Research Protocol, we obtained the ethics committee approval by the letter dated 7/26/2016, numbered 2011 of Bezmialem Foundation University and written consent was received from each volunteer participant. The data was analyzed by applying ANOVA (Analyze of Variance) and independent samples t-tests, using packaged software, SPSS 22 (Statistical Program for Social Sciences). The research limitations are implementing the study at only one unit and insufficient sample size. Therefore, the research results cannot be generalized to all the infertile individuals.

\section{Results}

We identified that out of the infertile individuals who entered into the study, $50 \%$ were between the ages of 26 and $30,73.4 \%$ were at a tertiary education level, the majority $(69.3 \%)$ were living in city, and $81 \%$ were in a nuclear family. It was seen that $65.3 \%$ of the participants were primarily infertile, $59.3 \%$ were expecting a baby for more than two years. $41.3 \%$ of them stated that they were having in mind the fact that the crux of the problem depends on woman and $62 \%$ declared that they were unhappy and very upset about the infertility case. We found that in Table 1, the point averages of RSES and FertiQol scores were affected by the gender of the participants and in both scales, the males had greater average than the females. We observed that in Table 2 , the age of the infertile females did not affect the RSES and FertiQol scores while the education level and quality life significantly affected the point averages, and the females of graduate and postgraduate education have higher quality of life than other groups. It was found that the points of both self-esteem and life quality were higher in the employed females. We determined that the way of marriage affected the point average of self-esteem at a statistically significant level and the females that were involuntarily married in the way of arranged marriage had lower self-esteem. It was detected that there was a statistically significant relationship between the family type and the RSES and FertiQol points and the type of nuclear family raised the sense of self-esteem of the females and increased their quality of life.

Table I The point averages of RSES and fertiqol scores of the infertile individuals and the relationship between the genders

\begin{tabular}{|c|c|c|c|c|c|c|c|c|c|c|}
\hline & \multicolumn{3}{|c|}{ Female $(n=100)$} & \multicolumn{3}{|c|}{ Male $(n=50)$} & \multicolumn{3}{|c|}{ Total(N=150) } & \multirow{2}{*}{$\mathbf{p}$} \\
\hline & Min & Max & Ave \pm SS & Min & Max & Ave \pm SS & Min & Max & Ave \pm SS & \\
\hline RSES Point Ave.* & 18 & 27 & $23.05 \pm 6.95$ & 23 & 26 & $23.84 \pm 4.38$ & 18 & 27 & $23.31 \pm 6.93$ & 0.049 \\
\hline FertiQol Point Ave.* & 35.75 & 97.68 & $75.45 \pm 6.16$ & 69.28 & 87.65 & $78.89 \pm 4.86$ & 35.75 & 97.68 & $76.63 \pm 6.86$ & 0.001 \\
\hline
\end{tabular}

$*=$ Independent Samples t-test $\quad \mathrm{P}<0.05$

We found that in Table 3, the age of the infertile males did not affect the points of RSES and FertiQoL while the education level affected the point average of life quality and that of the males of graduate and postgraduate education was higher than other groups. We observed that the employment increased the point of self-esteem in the males while the way of marriage had no effect on the points of self-esteem and life quality. It was seen that the family type did not affect the point of self-esteem but that of quality of life in the infertile males and those living in a nuclear family had higher quality of life. We determined that in Table 4, the type of infertility did not affect the average point of life quality in the females but had a statistically significant relationship with the point of self-esteem, and the selfesteem of the primary infertile group was higher. It was observed that in terms of the effect of infertility on an individual the point averages of both RSES and FertiQol scores changed at a statistically significant level and the females who were afraid of getting divorced had both lower self-esteem and quality life. We observed that in Table 5, the year to want to have a baby did not affect the point average of selfesteem in the infertile males but that of life quality and as long as that year was deferred the quality of life got lower. With regard to the effect of infertility on an individual, the point averages of both RSES and FertiQol scores changed at a statistically significant level 
and the males who expressed that they were feeling so sad due to the infertility had lower self-esteem and quality life than other groups. We observed that in Table 6, there was positive, reasonable relationship between the point averages of the scores that the infertile individuals got from both scales. As much as the quality of life increased in both the infertile females and males, their self-esteem increased.

Table 2 The comparison of the point averages of RSES and FertiQol scores of the infertile females and some socio-demographic attributes

\begin{tabular}{|c|c|c|c|c|c|}
\hline \multirow{2}{*}{ Descriptive Attributes } & \multicolumn{5}{|c|}{ Female $(\mathrm{N}=100)$} \\
\hline & Number & RSES $\pm S S$ & $p$ & 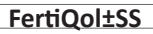 & $p$ \\
\hline \multicolumn{6}{|l|}{ Age Groups** } \\
\hline $20-25$ years & 27 & $23.48 \pm 2.65$ & \multirow{5}{*}{0.783} & $83.17 \pm 4.63$ & \multirow{5}{*}{0.2} \\
\hline $26-30$ years & 47 & $22.68 \pm 3.81$ & & $71.34 \pm 4.84$ & \\
\hline $31-35$ years & 18 & $23.50 \pm 3.93$ & & $73.54 \pm 4.26$ & \\
\hline $36-40$ years & 5 & $23.00 \pm 1.31$ & & $80.75 \pm 3.18$ & \\
\hline 41year and above & 3 & $22.33 \pm 3.28$ & & $74.17 \pm 3.24$ & \\
\hline \multicolumn{6}{|l|}{ Education Level $* *$} \\
\hline Literate & 15 & $22.14 \pm 2.84$ & \multirow{4}{*}{0.06} & $62.92 \pm 3.52$ & \multirow{4}{*}{$<0.001$} \\
\hline Middle School & 15 & $21.08 \pm 3.91$ & & $60.66 \pm 4.87$ & \\
\hline High School & 42 & $23.19 \pm 4.08$ & & $79.11 \pm 4.26$ & \\
\hline University or Higher & 28 & $23.89 \pm 3.10$ & & $84.76 \pm 4.32$ & \\
\hline \multicolumn{6}{|l|}{ Employment Status* } \\
\hline Employed & 52 & $23.67 \pm 2.81$ & \multirow{2}{*}{$<0.001$} & $81.24 \pm 4.69$ & \multirow[t]{2}{*}{0.034} \\
\hline Unemployed & 48 & $22.37 \pm 2.09$ & & $69.29 \pm 4.61$ & \\
\hline \multicolumn{6}{|l|}{ Way of Marriage** } \\
\hline Arranged/Involuntary & 12 & $21.91 \pm 1.92$ & \multirow{3}{*}{0.001} & $60.08 \pm 5.14$ & \multirow{3}{*}{0.104} \\
\hline Arranged/Voluntary & 42 & $22.78 \pm 3.91$ & & $82.85 \pm 4.06$ & \\
\hline Flirtingly & 46 & $23.58 \pm 2.63$ & & $71.85 \pm 3.98$ & \\
\hline \multicolumn{6}{|l|}{ Family Type* } \\
\hline Nuclear & 76 & $23.17 \pm 2.14$ & \multirow{2}{*}{0.015} & $77.77 \pm 5.85$ & \multirow[t]{2}{*}{0.007} \\
\hline Extended & 24 & $22.16 \pm 2.08$ & & $68.30 \pm 4.92$ & \\
\hline
\end{tabular}

*Independent samples t-test; **Single Direction Variance Analysis-F test; $\mathrm{p}<0.05$

Table 3 The comparison of the point averages of RSES and FertiQol scores of the infertile males and some socio-demographic attributes

\begin{tabular}{|c|c|c|c|c|c|}
\hline \multirow{2}{*}{ Descriptive Attributes } & \multicolumn{5}{|c|}{ Male $(\mathrm{N}=50)$} \\
\hline & Number & RSES $\pm S S$ & $p$ & FertiQol $\pm S S$ & $p$ \\
\hline \multicolumn{6}{|l|}{ Age Groups** } \\
\hline $20-25$ years & 7 & $24.28 \pm 1.31$ & \multirow{4}{*}{0.302} & $80.67 \pm 6.66$ & \multirow{4}{*}{0.201} \\
\hline $26-30$ years & 28 & $23.75 \pm 3.19$ & & $80.32 \pm 5.38$ & \\
\hline $31-35$ years & 7 & $24.00 \pm 1.03$ & & $77.45 \pm 5.11$ & \\
\hline $36-40$ years & 8 & $23.62 \pm 1.47$ & & $73.58 \pm 4.98$ & \\
\hline \multicolumn{6}{|l|}{ Education Level $* *$} \\
\hline Literate & 2 & $23.50 \pm 3.48$ & \multirow{4}{*}{0.71} & $71.34 \pm 1.38$ & \multirow{4}{*}{0.014} \\
\hline Middle School & 8 & $23.27 \pm 2.91$ & & $74.04 \pm 2.88$ & \\
\hline High School & 11 & $24.27 \pm 3.54$ & & $79.55 \pm 3.49$ & \\
\hline University or Higher & 29 & $23.82 \pm 3.12$ & & $80.01 \pm 4.11$ & \\
\hline \multicolumn{6}{|l|}{ Employment Status* } \\
\hline Employed & 46 & $24.25 \pm 2.59$ & \multirow{2}{*}{$0.002 *$} & $78.55 \pm 2.88$ & \multirow{2}{*}{0.201} \\
\hline Unemployed & 4 & $23.80 \pm 1.68$ & & $79.12 \pm 1.30$ & \\
\hline \multicolumn{6}{|l|}{ Way of Marriage ** } \\
\hline Arranged/Involuntary & 4 & $23.50 \pm 4.39$ & \multirow{3}{*}{0.064} & $75.81 \pm 2.61$ & \multirow{3}{*}{0.163} \\
\hline Arranged/Voluntary & 26 & $23.76 \pm 5.18$ & & $79.97 \pm 3.09$ & \\
\hline Flirtingly & 20 & $24.00 \pm 4.77$ & & $78.10 \pm 3.01$ & \\
\hline \multicolumn{6}{|l|}{ Family Type* } \\
\hline Nuclear & 46 & $24.89 \pm 4.94$ & \multirow{2}{*}{0.109} & $79.41 \pm 4.10$ & \multirow{2}{*}{0.008} \\
\hline Extended & 4 & $23.25 \pm 2.88$ & & $72.91 \pm 2.31$ & \\
\hline
\end{tabular}

*Independent samples t-test; **Single direction variance analysis-F test; 
Table 4 The comparison of the point averages of RSES and FertiQol scores of females and some obstetric and infertility attributes

\begin{tabular}{|c|c|c|c|c|c|}
\hline \multirow{2}{*}{ Attributes } & \multicolumn{5}{|c|}{ Females $\mathrm{N}=100$} \\
\hline & Number & RSES $\pm S S$ & $\mathbf{p}$ & FertiQol $\pm S S$ & $\mathbf{p}$ \\
\hline \multicolumn{6}{|l|}{ Type of Infertility* } \\
\hline Primary & 62 & $23.37 \pm 2.18$ & \multirow{2}{*}{0.031} & $78.73 \pm 4.69$ & \multirow{2}{*}{0.253} \\
\hline Secondary & 38 & $22.52 \pm 1.98$ & & $70.21 \pm 3.75$ & \\
\hline \multicolumn{6}{|l|}{ The year to wanna have a baby** } \\
\hline$<2$ Year & 28 & $23.50 \pm 2.92$ & \multirow{4}{*}{0.227} & $81.71 \pm 4.03$ & \multirow{4}{*}{0.692} \\
\hline 3-5 Year & 41 & $23.30 \pm 1.23$ & & $76.16 \pm 4.12$ & \\
\hline 6-8Year & 27 & $22.50 \pm 1.61$ & & $72.23 \pm 3.35$ & \\
\hline$>9$ Year & 4 & $22.61 \pm 3.08$ & & $73.26 \pm 0.91$ & \\
\hline \multicolumn{6}{|l|}{ Effect of Infertility** } \\
\hline Feeling so sad & 45 & $22.80 \pm 3.81$ & & $74.91 \pm 4.35$ & \\
\hline Afraid of getting divorced & 5 & $23.00 \pm 1.02$ & & $60.01 \pm 6.40$ & \\
\hline Feeling ashamed of my husband and family & 3 & $22.33 \pm 2.30$ & 0.008 & $76.94 \pm 5.80$ & 0.025 \\
\hline Very unhappy & 17 & $22.88 \pm 1.71$ & & $77.09 \pm 2.34$ & \\
\hline Nothing has changed & 30 & $23.60 \pm 2.88$ & & $77.74 \pm 3.01$ & \\
\hline
\end{tabular}

*Independent samples $t$-test; **Single direction variance analysis- $\mathrm{F}$ test; $\mathrm{p}<0.05$

Table 5 The comparison of the point averages of RSES and FertiQol scores of males and some obstetric and infertility attributes

\begin{tabular}{|c|c|c|c|c|c|}
\hline \multirow{2}{*}{ Attributes } & \multicolumn{5}{|c|}{ Males $(\mathrm{N}=50)$} \\
\hline & Number & RSES $\pm S S$ & $\mathbf{p}$ & FertiQol $\pm S S$ & $\mathbf{p}$ \\
\hline \multicolumn{6}{|l|}{ Type of Infertility* } \\
\hline \multirow[t]{2}{*}{ Primary } & 36 & $23.97 \pm 4.82$ & & $80.33 \pm 3.91$ & \\
\hline & & & 0.062 & & 0.391 \\
\hline Secondary & 14 & $23.50 \pm 1.28$ & & $75.16 \pm 2.36$ & \\
\hline \multicolumn{6}{|l|}{ The year to wanna have a baby** } \\
\hline$<2$ Year & 33 & $23.96 \pm 4.36$ & & $80.52 \pm 3.94$ & \\
\hline \multirow[t]{2}{*}{ 3-5 Year } & 10 & $23.70 \pm 3.58$ & & $76.26 \pm 4.02$ & \\
\hline & & & 0.344 & & 0.001 \\
\hline 6-8Year & 3 & $23.33 \pm 2.88$ & & $78.28 \pm 2.61$ & \\
\hline$>9$ Year & 4 & $23.50 \pm 2.41$ & & $72.47 \pm 2.89$ & \\
\hline \multicolumn{6}{|l|}{ Effect of Infertility** } \\
\hline Feeling so sad & 12 & $23.41 \pm 1.89$ & & $76.41 \pm 1.93$ & \\
\hline Afraid of getting divorced & - & - & & - & \\
\hline $\begin{array}{l}\text { Feeling ashamed of my husband and } \\
\text { family }\end{array}$ & - & - & 0.004 & - & $<0.001$ \\
\hline Very unhappy & 19 & $23.68 \pm 2.91$ & & $77.07 \pm 3.08$ & \\
\hline Nothing has changed & 19 & $24.26 \pm 3.14$ & & $82.27 \pm 3.62$ & \\
\hline
\end{tabular}

*Independent samples t-test; $* *$ Single direction variance analysis- $\mathrm{F}$ test; $\mathrm{p}<0.05$ 
Table 6 The relationship between RSES and FertiQol scoring

\begin{tabular}{ll}
\hline & $\mathbf{r}$ \\
\hline Total $(\mathrm{N}=150)$ & 0.645 \\
FertiQol RSES & \\
Females $(\mathrm{n}=100)$ & 0.666 \\
FertiQol RSES & \\
Males $(\mathrm{n}=50)$ & \\
FertiQol RSES & 0.402 \\
\hline
\end{tabular}

r, Pearson correlation

\section{Discussion}

As being in the world, also in Turkey, child is a significant component of marriage. In many marriages, families and social circles put a pressure on the childless couples. The couples diagnosed with infertility feel much more pressure than other couples because the infertility treatment has some psychological, social and economic effects. In particular, due to the cultural reasons, it is much harder to accept the diagnosis of infertility and hence share it with his family and surrounding and the health professionals for a man. ${ }^{16}$ Due to the fact that men are more reluctant to apply to the infertility clinics than women a limited number of men entered into our study. In similar studies, it is also noted that the participation in treatment and fellowship of the infertile men are insufficient. ${ }^{17-19}$ We observed that the infertile women have lower self-esteem and quality of life than the infertile men. It is stated that the infertility that is perceived as a stressful experience negatively affect the individual life in Turkey and also all over the world, and it has more effect upon the women, in particular. ${ }^{20,21}$ The study that Wischmann et al..$^{22}$ conducted with 158 infertile females and 153 infertile males suggested that the selfesteem of women is lower than that of the men. ${ }^{22}$ Typically, in a study made by Teskereci in 2010 it is specified that the infertile males have higher quality of life than the infertile females in Turkey. ${ }^{23}$ It is acknowledged that the infertile individuals of lower education are more sensitive to social stigma and as a result, more prone to stress. ${ }^{17,24}$ In this study, it is observed that the education level positively affect the quality of life in the infertile individuals. As the educational level increases, the individual easily adapts to the process and accordingly his or her quality of life increased. In the study of Alibaşoğlu ${ }^{17}$ the infertile individuals of lower education level the levels of depression and situational anxiety level are higher and the dyadic adjustment is inadequate. ${ }^{17}$

We observed that the point of self-esteem of the infertile males employed was higher than that of the unemployed ones. It is determined that out of the infertile females employed had both higher point of self-esteem and quality of life, compared to those unemployed. In the studies of Upkong and Orjii ${ }^{25}$ and Ramezanzadeh et al. ${ }^{26}$ it is specified that the depression and anxiety subject to infertility are less detected in the employed women. ${ }^{25,26}$ These results suggest that the self-confidence and social status of the infertile women employed increased by finding the self-actualization chance in an environment outside of their homes and by this means, they can better adapt to the infertility treatment program. In Turkey, some part of the individuals is living in an extended family. Those feel much more pressure of the failure to have baby. ${ }^{27-29}$ In this study, we found that the family type negatively affected the point of life quality in the males and both the points of self-esteem and quality of life in the females. Monga et al. ${ }^{30}$ suggested in their study that $83.3 \%$ of the infertile couples were feeling pressure now that they are not able to have baby and point out their parents and friends as its source ${ }^{30}$ The time to want to have baby distinctly affects the self-esteem and life quality of the infertile individuals. Xin et al. ${ }^{31}$ observed in their study made in 2013 that as that time lengthens out the individuals lose their self-esteem and self confidence..$^{31}$ Differently from this, Güz et al..$^{32}$ suggested in the study that the infertility duration increases the individuals accept the situation and accommodate themselves over time and their anxiety level reduces. ${ }^{32}$ In our study we determined that the quality of life decreases in the infertile males as the infertility duration increases.

In the traditional countries like Turkey, the infertility is not perceived as a health issue but a deficiency or defect. Especially the women are charged with this. Keskin and Babacan Gümüş suggested in the study (2014) that the women stated that the infertility causes such effects as sadness, unhappiness, desperateness, shamefacedness from their husband and family, and being afraid of getting divorced. ${ }^{33}$ In our study, we observed that out of the infertility effects, the women marking the choice of "I am ashamed of my spouse and family" had lower self-esteem than others. It was also seen that the men never ticked up the choices of "I am ashamed of my spouse and family" and "I am afraid of getting divorced" and they didn't hold themselves accountable. Sen et al. ${ }^{34}$ specified in his study (2014) that $43.9 \%$ of the women were worried about being blamed by their family. ${ }^{34}$ In our study, we found that there was a statistically significant relationship between the RSES and FertiQol scores. It was observed that as the point of quality of life increases that of self-esteem increases in both the males and the females in our sample groups. In a similar manner, Keramat et al..$^{35}$ determined in the study which they conducted using Who-Qol-BREF and FertiQol that there was a statistically significant relationship of two scales. According to that study, the self-esteem of the infertile individuals increased in parallel with their quality of life..$^{35}$ In the FertiQol scoring that we used to determine the life quality of the infertile individuals, the items, such as "Can you get the treatment services that you want?", "Do you find the given information about this issue adequate?", "Are you satisfied with the communication of the treatment team?", and "Are you feeling that the treatment team is understanding what you experience?", indicate the role of nurses in improving the life quality of the infertile individuals. An infertility nurse can effectively enhance their quality of life and so self-esteem by means of a quality treatment program.

\section{Conclusion}

We specified that the study results evidenced the research questions and the socio-demographic and obstetric characteristics of the infertile individuals affect their sense of self-esteem and quality of life. We observed that the infertility negatively affected both self-esteem and quality of life for both genders. We found that the life quality of the infertile man and woman increased as their education level increased and the employment positively affected self-esteem. We determined that the infertile women who were married by flirting had higher selfesteem and those who were living in a nuclear family had both higher self-esteem and quality of life.

\section{Acknowledgements}

None. 


\section{Conflict of interest}

Authors declare that there is no conflict of interest.

\section{References}

1. Manual for the standardized investigation and diagnosis of infertile couple WHO. Cambridge University Press. 2000; 1-51.

2. Hacker NF, Moore JG, Gambone JC. Essentials of Obstetrics and Gynecology. $4^{\text {th }}$ edn; 2004.

3. Atasü T, Şahmay S, İstanbul: Nobel Tıp Kitabevi. Jinekoloji, (Gynecology) Nobel Medical Press; 2001.

4. Sezgin H, Hocaoğlu Ç. Psychological Aspect of Infertility. Contemporary Approaches in Psychiatry. 2014;6(2):165-184

5. Hoffman BL, Schorge JO, Schaffer JI, et al. Williams Gynecology. 2015.

6. Coşkun AM. Manual for the Nursing for Women's Health and Gynecological Diseases. İstanbul: KoçÜniversitesi Yayınları. Koç University Press. 2012

7. Akyüz A. Nursing care in the adaptation to the negative result of IVF treatment (a dissertation study) Ankara: Gülhane Military Medical Academy. 2001

8. Partovi Meran HE, KizllkayaBeji N. History of Infertility Nursing. Andrologia Bulletin. 2016;18(64):60-64.

9. Engin R, Pasinlioğlu T. Traditional beliefs and practices of infertility in the women in Erzurum and its region. Atatürk University Nursing Higher School Journal. 2002; 5(1):1-5.

10. Bolsoy N, Taşpınar A, Kavlak O, et al. Differences in quality of life between infertile women and men in Turkey. J Obstet Gynecol Neonatal Nurs. 2010;39(2):191-198.

11. Monga M, Alexandrescu B, Katz SE, et al. Impact of Infertility on Quality of Life, Marital Adjustment and Sexual Function. Urology. 2004;63(1):126-130.

12. Kızılkaya Beji N, Kaya D. Individual \& Couple Counseling in Infertility. The Journal of Education and Research in Nursing. 2012;9(3):10-14.

13. Kurçer MA, ve Ark. The attitudes of infertile women towards the traditional previleged infertility treatments and the influencing factors. The Journal of TurgutÖzal Medical Centre. 1999;6(4).

14. Ataman H. Psycho-social treatment requirements for the natural pregnancies and the pregnancies occurring after infertility treatment. $A$ thesis study. İstanbul: Marmara University; 2007.

15. Karaca A, Ünsal G. The Effects of Infertility on Women's Mental Health and the Role of Psychiatric Nurses. Psychiatric Nursing Journal. 2012;3(2),80-85.

16. Göker Tamay A, Koyuncu FM. Sexual Dysfunction in infertile couples, and quality of life. Turkish Clinics Gynecology Obstetrics Journal. 2012;5(2):97-102.

17. Alibaşoğlu H. Emotional Symptoms in Infertility, Marital Adjustment, and Gender Differences in the context of Sexual Functioning. (A medical dissertation), Bakırköy Professor Mazhar Osman Mental Health and Neurological Diseases Education and Research Hospital, İstanbul. 2010.
18. Berg BJ, Wilson JF, Weingartner PJ. Psychological sequelae of infertility treatment: the role of gender and sex-role identification. Soc Sci Med. 1991;33(9):1071-80.

19. Black LD, Delgado JD, Turek PJ. The infertility issue: Who says men don't talk? Fertil Steril. 2001;76(3):198.

20. Oğuz HD. The effects of infertility on mental health, marital relationship, and sexual life in the women undergoing infertility treatment (A medical dissertation), Bakırköy Professor Mazhar Osman Mental Health and Neurological Diseases Education and Research Hospital, İstanbul. 2004.

21. Harrison KL, Callan VJ, Hennesey JF. Stress and semen quality in an in vitro fertilization program. Fertil Steril. 1987;48(4):633-6.

22. Wischmann T, Schilling K, Toth B, et al. Sexuality, Self-Esteem and Partnership Quality in Infertile Women and Men. Geburtshilfe Frauenheilkd.2014;74(8):759-763.

23. Teskereci G. The effect of life style upon life of quality in the couples undergoing infertility treatment. (A thesis study), Akdeniz University, Antalya; 2010.

24. OnatBayram G. The Effect of Infertility on Life of Quality and Marita Adjustment. (A dissertation study), İstanbul University, İstanbul; 2009.

25. Upkong D, Orji EO. Mental Health in the Infertile Women in Nigeria. Turk Psikiyatri Derg, 2006;17(4); 259-265.

26. Ramezanzadeh F, Aghssa MM, Abedinia N, et al. Surveying of Relationship Between Anxiety, Depression and Duration of Infertility. International Congress Series. 2004;1271:334-337.

27. Çetinbaş A. Life Quality in the Women Applying to the Assisted Reproductive Techniques Center at Trakya University. (A dissertation study), Trakya University, Edirne; 2014.

28. UyarBetül. The Level of Belief in Sexual Myths in the Women Undergoing Infertility Treatment. Dicle University, Diyarbakır; 2015.

29. Öztürk T. The gender differences with regard to anxiety, depression, attitudes in handling stress, trait anger, and anger expression (A medical dissertation), Bakırköy Professor Mazhar Osman Mental Health and Neurological Diseases Education and Research Hospital, İstanbul; 2011

30. Monga M, Alexandrescu B, Katz SE, et al. Impact of Infertility on Quality of Life, Marital Adjustment and Sexual Function. Urology. 2004; 63(1):126-130.

31. Xin X, Pan BC, Du Q, et al. Impact of Male Infertility on Men's Self esteem and Satisfaction with Sexual Relationship. Zhonghua Nan KeXue. 2013;19(3): 223-227.

32. Güz H, Özkan A, Sarısoy G, et al. Psychiatric symptoms in Turkish infertile women. J Psychosom Obstet Gynaecol. 2003;24(4):267-271.

33. Keskin G, Babacan Gümüş A. Infertility: A Review in the perspective of Despair. Psychiatric Nursing Journal. 2014;5(1):9-16.

34. Şen E, Bulut S, Şirin A. Reviewing the Marital Adjustment in Primary Infertile Women. FN Hem Dergisi. 2014;22(1):17-24.

35. Keramat A, Masoomi SZ, Mousavi SA, et al. Quality of Life And its Related Factors in Infertile Couples. J Res Health Sci. 2014;14(1):57-63. 